\title{
A commensal symbiotic interrelationship for the growth of Symbiobacterium toebii with its partner bacterium, Geobacillus toebii
}

Kwang Kim ${ }^{1}$, Joong-Jae Kim ${ }^{1,5}$, Ryoji Masui ${ }^{1,4}$, Seiki Kuramitsu ${ }^{1,4^{*}}$ and Moon-Hee Sung ${ }^{2,3^{*}}$

\begin{abstract}
Background: Symbiobacterium toebii is a commensal symbiotic thermophile that absolutely requires its partner bacterium Geobacillus toebii for growth. Despite development of an independent cultivation method using cell-free extracts, the growth of Symbiobacterium remains unknown due to our poor understanding of the symbiotic relationship with its partner bacterium. Here, we investigated the interrelationship between these two bacteria for growth of $S$. toebii using different cell-free extracts of $G$. toebii.

Results: Symbiobacterium toebii growth-supporting factors were constitutively produced through almost all growth phases and under different oxygen tensions in $G$. toebii, indicating that the factor may be essential components for growth of $G$. toebii as well as $S$. toebii. The growing conditions of $G$. toebii under different oxygen tension dramatically affected to the initial growth of $S$. toebii and the retarded lag phase was completely shortened by reducing agent, L-cysteine indicating an evidence of commensal interaction of microaerobic and anaerobic bacterium S. toebii with a facultative aerobic bacterium G. toebii. In addition, the growth curve of S. toebii showed a dependency on the protein concentration of cell-free extracts of $G$. toebii, demonstrating that the $G$. toebii-derived factors have nutrient-like characters but not quorum-sensing characters.

Conclusions: Not only the consistent existence of the factor in G. toebii during all growth stages and under different oxygen tensions but also the concentration dependency of the factor for proliferation and optimal growth of S. toebii, suggests that an important biosynthetic machinery lacks in S. toebii during evolution. The commensal symbiotic bacterium, S. toebii uptakes certain ubiquitous and essential compound for its growth from environment or neighboring bacteria that shares the equivalent compounds. Moreover, G. toebii grown under aerobic condition shortened the lag phase of $S$. toebii under anaerobic and microaerobic conditions, suggests a possible commensal interaction that G. toebii scavengers ROS/RNS species and helps the initial growth of S. toebii.
\end{abstract}

Keywords: Symbiobacterium toebii, Geobacillus toebii, Bacterial symbiosis, Growth-supporting factor, Commensalism

\section{Background}

Approximately 99\% of microorganisms in natural environments have been estimated as being uncultivable using current methods. Technical difficulties arise because the constitution of microbial communities remains largely unknown [1-3], and thus adequate understanding of their diversity remains elusive. Until

\footnotetext{
* Correspondence: kuramitu@bio.sci.osaka-u.ac.jp; smoonhee@kookmin.ac.kr 'Department of Biological Sciences, Graduate School of Science, Osaka University, Osaka 560-0043, Japan

${ }^{2}$ BioLeaders Corporation, 559 Yongsan-dong, Yuseong-gu, Daejeon 350-500, Korea

Full list of author information is available at the end of the article
}

now, no detailed research had examined interspecies communication amongst uncultivable microorganisms even though progressive analyzing methods such as fluorescence in situ hybridization - microautoradiography [4,5], stable-isotope probing [6,7], and isotope array [8] had been reported to monitor a community of countless microorganism group in special environmental samples. Information was limited to how growth of uncultivable cells is affected by that of other microorganisms, how these cells progress to death or a dormant state and how growth is induced. At the same time, however, important findings concerning the commensal

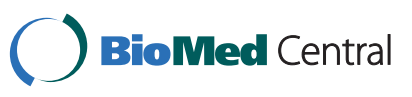


symbiotic and parasitic relationships between bacteria and eukaryotes, as well as cell-to-cell communication within a bacterial species, were being made [9-12].

Recent research on uncultivable microorganisms has led to a new cultivation method to isolate such microorganisms from nature. As a representative report, Kaeberlein and colleagues reported an in situ cultivation method to construct a simulated natural environment using a diffusion chamber that can provide certain growth-associated factors originating from adjacent microorganisms [13]. As similar approaches for the study of uncultivable microorganisms, we had developed a simple cultivation method by using either cell-free extract (CFE) or culture supernatant of its cognate bacteria to supply certain growth-supporting factor (GSF) for a commensal uncultivable bacterium [14]. Using the direct cultivating method with CFE of partner bacterium, we successfully isolated an intriguing bacterium from compost in the natural environment. The taxonomic analysis using $16 \mathrm{~S}$ rDNA sequence revealed that it belonged to Symbiobacterium, in which growth absolutely depends on co-existence of the helper bacterium, Geobacillus species [14,15]. Studies of the distribution and diversity of Symbiobacterium species using competitive quantitative PCR, terminal restriction fragment length polymorphism and denaturing gradient gel electrophoresis revealed that these bacteria are widespread in natural environments, including compost, animal faeces, feeds and soils [16-19].

In our previous reports, we showed that Symbiobacterium species absolutely require an unidentified Symbiobacterium toebii growth-supporting factor (sytoGSF) from partner bacteria for their growth and showed no growth under artificial culture conditions without G. toebii $[14,15,20]$. Despite the development of pure cultivation methods for Symbiobacterium, the isolation and cultivation of this genus remain difficult due to the lack of information on rigorous culture conditions, its growth mechanisms and symbiotic relationships with partner bacteria. In addition, the fundamental question as to what the sytoGSFs are also remains debatable. Despite extensive studies on independent culture systems, the low reproducibility of axenic cultivation of $S$. toebii demonstrates that it has a complicated relationship with the partner bacterium, G. toebii, and also demands strict culture conditions for stable proliferation.

Moreover, no study has been reported to the relationship between two commensal bacteria for the initial growth of $S$. toebii and to the conditions for production of sytoGSFs from G. toebii, meanwhile the study about the characters of sytoGSFs produced by partner bacteria were relatively focused on the commensal symbiosis between S. toebii and G. toebii [20]. Understanding this representative relationship for commensal symbiosis between two different genera will give insights into basic information to elucidate the growth mechanism of other uncultivable bacteria which absolutely need GSF for its growth. We hope that this report could contribute to the cultivation of novel bacteria contained in $99 \%$ of the uncultivated bacteria of nature.

\section{Results}

sytoGSFs are produced in almost all growth stages of $G$. toebii

In mixed cultivation of S. toebii with G. toebii, we previously reported that growth of $S$. toebii initiated and promoted after co-culture with $G$. toebii reached a stationary phase [14]. However, when sytoGSFs are produced from partner bacteria is remaining controversial. To clarify this fundamental question, we proposed two hypotheses: (i) G. toebii sytoGSFs are produced and secreted into the culture medium during the stationary phase similar to secondary metabolites, or (ii) sytoGSFs are constitutively produced at every growth stage and are accumulated and released into the culture medium at stationary phase by cell lysis.

To define the production phase of sytoGSFs from $G$. toebii, we investigated growth-supporting activity using the same amount of cell-free extracts of G. toebii (GtoCFEs) extracted from each of three different growth phases of G. toebii, the lag phase ( 2 h cultivation), midexponential phase $(9 \mathrm{~h})$ and stationary phase $(24 \mathrm{~h})$. Nitrite production and optical density were used to assess the growth of $S$. toebii in response to each GtoCFE. Figure 1 shows that all three GtoCFEs had similar effects on the growth of $S$. toebii. The effects of GtoCFEs prepared from lag and exponential phase cells showed similar doubling times and optimal nitrite production to the stationary phase-extracted GtoCFEs, suggesting that G. toebii constantly produced sytoGSFs throughout almost all growth stages.

\section{Growth of S. toebii depends on the concentration of GtoCFEs}

In Figure 1, the result of growth-supporting activity against the growth phase-dependent GtoCFEs was consistent with the second hypothesis and suggested that a low cell mass of G. toebii at the lag phage produced a small amount of sytoGSFs. We consider that the extended lag phase of $S$. toebii in mixed cultivation with G. toebii [14] caused by insufficient amounts of sytoGSFs leads to exponential growth of S. toebii when G. toebii reached stationary phase and that this bacterium requires a certain concentration of sytoGSFs for its stable proliferation.

To investigate the effect of the concentration of sytoGSFs required for stable growth, we examined the maximum growth rate of $S$. toebii in the presence of 

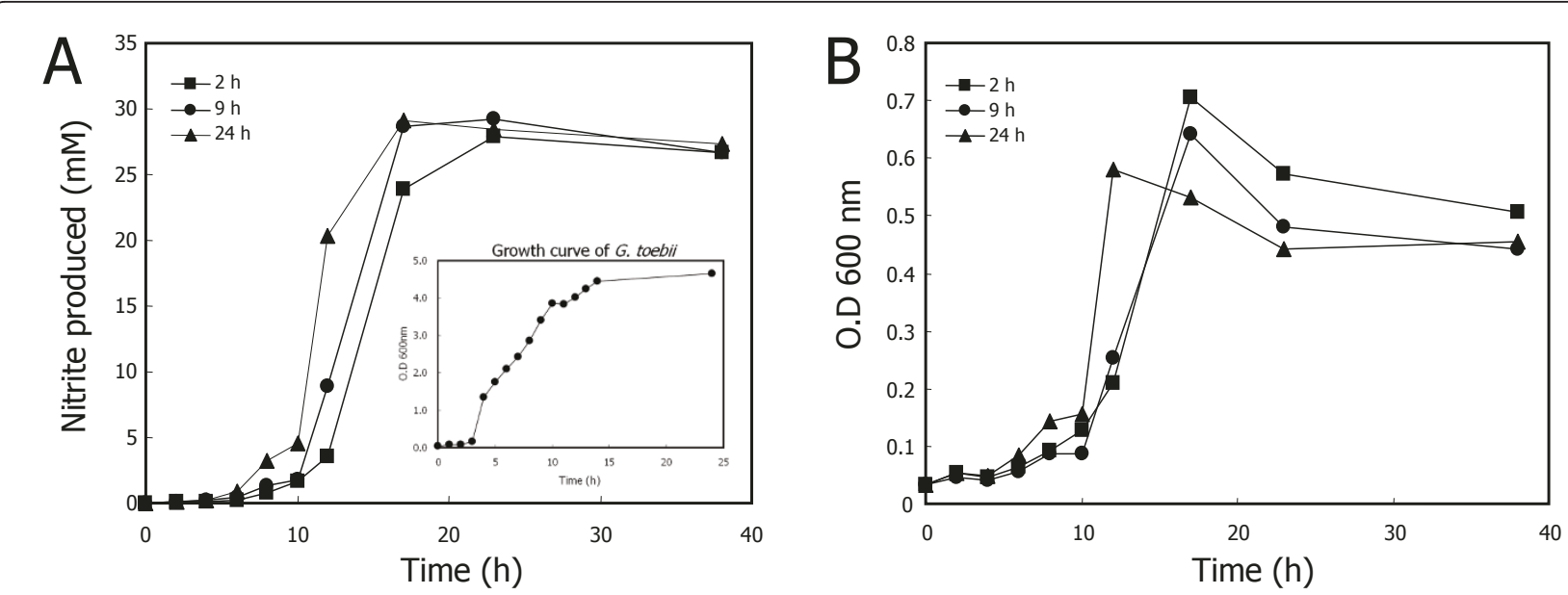

Figure 1 Comparison of S. toebii growth curves and dependence on cell-free extracts from various $G$. toebii growth stages. S. toebii was inoculated and cultured at $60^{\circ} \mathrm{C}$ in $100 \mathrm{ml} \mathrm{PEPN}$ broth under anaerobic conditions with $200 \mathrm{\mu g} \mathrm{ml}^{-1}$ GtoCFE prepared from various G. toebii growth stages. G. toebii was cultured for $2 \mathrm{~h}$ (lag phase, squares), $9 \mathrm{~h}$ (exponential phase, circles) and $24 \mathrm{~h}$ (stationary phase, triangles), and then CFEs were prepared. The $\mathrm{G}$. toebii growth curve (as measured by optical density at $600 \mathrm{~nm}$ ) is shown in the inset (panel A). S. toebii growth was monitored by nitrite production (A) and optical density at $600 \mathrm{~nm}$ (B).

GtoCFE protein concentrations ranging from $5.0 \mu \mathrm{g}$ $\mathrm{ml}^{-1}$ to $300 \mu \mathrm{g} \mathrm{ml}^{-1}$ (Figure 2). After $18 \mathrm{~h}$ of cultivation of $S$. toebii under anaerobic conditions, optimal growth was achieved with more than $60 \mu \mathrm{g} \mathrm{ml}^{-1}$ protein of the GtoCFE. With $30 \mu \mathrm{g} \mathrm{ml}^{-1}$ GtoCFE, only half-maximal growth was achieved, indicating that the growth rate of S. toebii depends on the concentration of factors in the GtoCFE. In addition, we investigated growth curves of $S$. toebii against various GtoCFE protein concentrations by measuring nitrite production, optical density $(600$

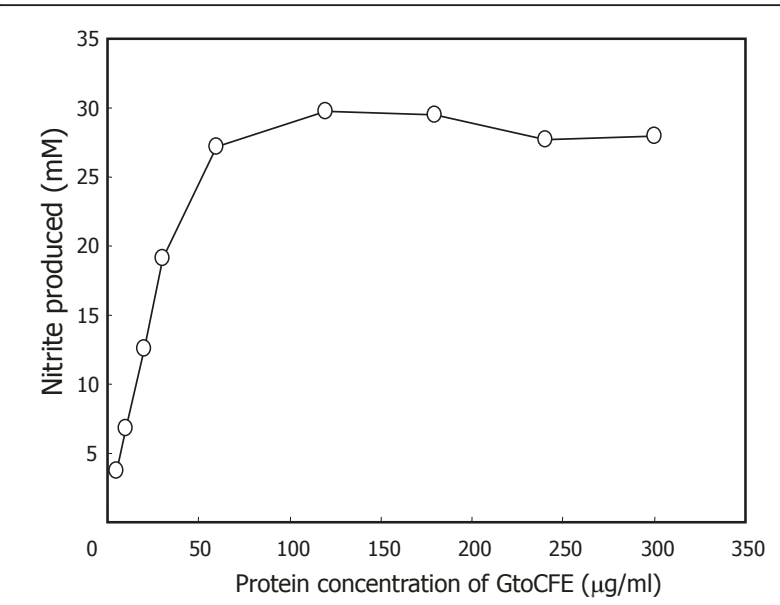

Figure 2 Growth of S. toebii depends on the concentration of GtoCFE. S. toebii was cultivated at various concentrations of GtoCFE in $10 \mathrm{ml}$ PEPN broth at $60^{\circ} \mathrm{C}$ in an anaerobic jar with a GasPak ${ }^{\mathrm{TM}}$ Plus Anaerobic System Envelope for $18 \mathrm{~h}$. The $x$-axis indicates the final protein concentration of the supplied GtoCFE in the culture broth. S. toebii growth was monitored by nitrite production. $\mathrm{nm}$ ) and viable cell counts to verify the growth-supporting effect of GtoCFEs (Figure 3). A high concentration of GtoCFE (e.g., $\geq 50 \mu \mathrm{g} \mathrm{ml}^{-1}$ ) supported rapid and optimal growth of $S$. toebii within $17 \mathrm{~h}$, but $10 \mu \mathrm{g}$ $\mathrm{ml}^{-1}$ GtoCFE did not substantially enhance the growth. Compared to $100 \mu \mathrm{g} \mathrm{ml}^{-1}$ GtoCFE, the growth rate and doubling time were significantly retarded in the presence of $20 \mu \mathrm{g} \mathrm{ml}^{-1}$ GtoCFE. These results strongly suggest that sytoGSFs have a role as nutrient-like compounds and S. toebii requires sytoGSFs throughout its all growth phases.

The culture conditions of $G$. toebii under different oxygen tension affect the growth of $S$. toebii

Figure 1 showed that G. toebii constantly produced sytoGSFs throughout almost all growth phases. However, G. toebii was cultivated under aerobic conditions for both of this experiment and previous reports, even though S. toebii cannot grow under aerobic conditions [21]. Since anaerobic or microaerobic conditions are essential for a commensal interaction between these two bacteria, we doubted that G. toebii could produce sytoGSFs under microaerobic or anaerobic conditions. We reported that G. toebii can grow under aerobic conditions [22], but we recently found it can also grow under anaerobic and microaerobic conditions with nitrate as an electron acceptor. The optical density (600 $\mathrm{nm}$ ) of culture broth of G. toebii at early stationary phase under the microaerobic and anaerobic conditions showed about 0.6 and the growth of G. toebii under both conditions was almost parallel (data not shown). Based on this result, we were able to prepare GtoCFEs 

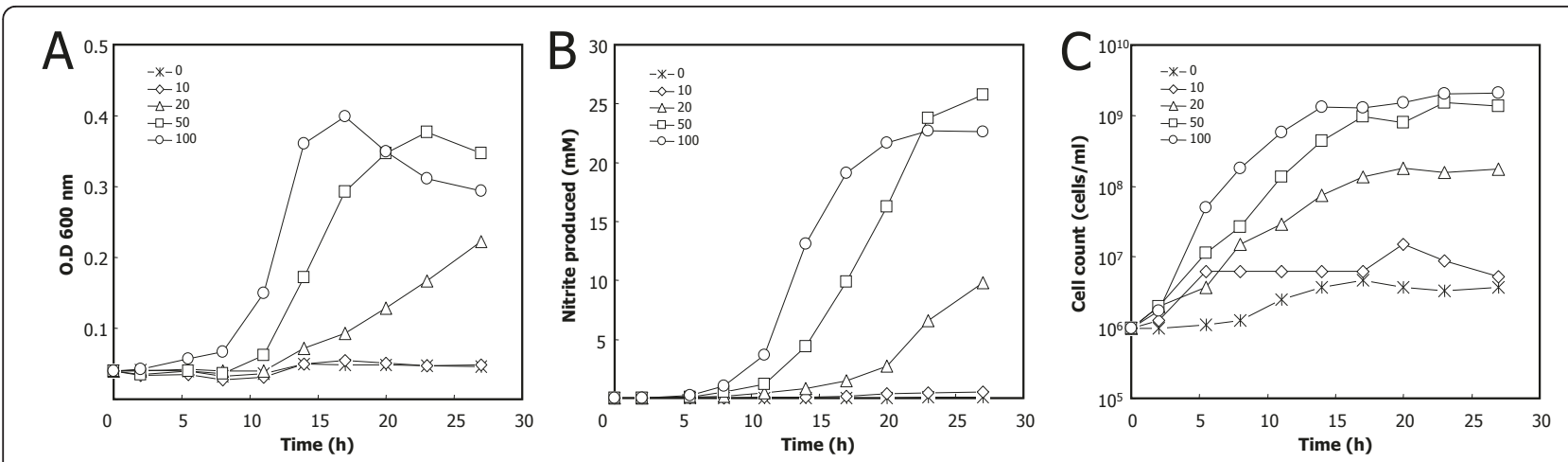

Figure 3 Growth curve of S. toebii with respect to GtoCFE concentration. One milliliter of anaerobically $12 \mathrm{~h}$-cultured S. toebii was inoculated and cultured at $60^{\circ} \mathrm{C}$ in $100 \mathrm{ml} \mathrm{PEPN}$ broth in a $\mathrm{N}_{2}$ gas-flushed anoxic cultivation system with 0, 10, $20,50 \mathrm{or} 100 \mu \mathrm{g} \mathrm{ml}{ }^{-1} \mathrm{GtoCFE}$. The growth of S. toebii was monitored by measuring the optical density at $600 \mathrm{~nm}$ (A), concentration of nitrite produced (B) and cell counts (C).

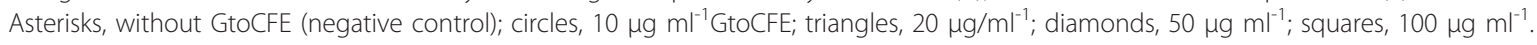

from anaerobically and microaerobically cultivated $G$. toebii and determined the growth-supporting effect for S. toebii.

Figure 4 shows that similar maximum growth can be achieved with all three supplements after $48 \mathrm{~h}$ cultivation. We noted that $S$. toebii cultured with GtoCFEs of aerobically cultured G. toebii had a 5-h lag time, whereas the lag times of $S$. toebii cultured with GtoCFEs prepared from microaerobically and anaerobically cultured cells were significantly extended to approximately $30 \mathrm{~h}$. Moreover, all three GtoCFEs

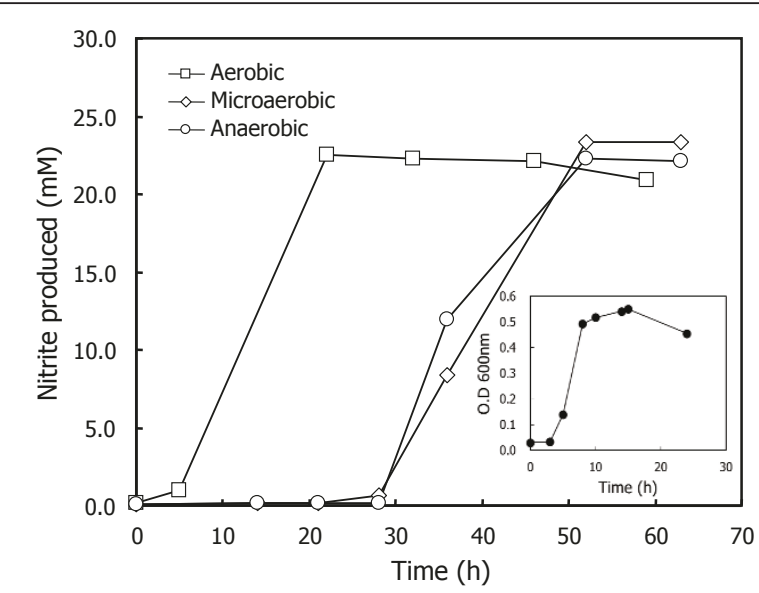

Figure 4 Effects of GtoCFE prepared under various culture conditions on S. toebii growth curves. S. toebii was cultured in a $\mathrm{N}_{2}$ gas-flushed anoxic cultivation system with $0.2 \mathrm{mg} \mathrm{ml}^{-1}$ of various GtoCFEs (squares, prepared from aerobic culture; diamonds, prepared from microaerobic culture; circles, prepared from anaerobic culture). Each $G$. toebii was cultured for overnight under different culture conditions and the cell-free extract was prepared by following the methods section. Nitrite production was used as a measure of S. toebii growth. The G. toebii growth curve (as measured by optical density at $600 \mathrm{~nm}$ ) under the anaerobic culture condition was shown in the inset. showed similar growth-supporting effects at the doubling time. This indicates that G. toebii can also produce sytoGSFs under anaerobic and microaerobic culture conditions as well as under aerobic conditions. Furthermore, some factors contained in aerobically cultivated G. toebii dramatically support the initial growth of S. toebii.

\section{Reducing agent recovered the extended lag time of $S$. toebii}

The results in Figure 4 suggest that GtoCFEs from microaerobically and anaerobically cultured G. toebii lack some factors necessary for adaptation and initial growth of $S$. toebii during the lag phase. Because $S$. toebii was quite sensitive to the oxygen tension, we further hypothesised that the CFE of aerobically cultured G. toebii contains plentiful machinery that eliminates toxicity against oxidative stresses by reactive oxygen and nitrogen species (ROS/RNS) in the culture medium. Furthermore, almost aerobic bacteria have enzymatic defense systems (e.g., superoxide dismutase, catalase and peroxidase) against oxidative stress [23,24].

To investigate the effect of oxidative stress on lag time and examine whether an enzymatic defense system against ROS works in the GtoCFE supplied culture broth of S. toebii, we tested the effect of L-cysteine, a reducing agent known to alter the redox state of culture broth [25], in the culture broth that contained microaerobically or anaerobically prepared GtoCFEs for growth of S. toebii. The addition of $0.025 \%$ L-cysteine significantly shortened the lag time for GtoCFEs prepared with microaerobically or anaerobically cultured cells (Figure 5). Furthermore, the doubling times at the exponential growth stage were similar to those of aerobically prepared GtoCFEs. This result suggests that reduction of ROS/RNS by the enzymatic defense system in culture broth containing with aerobically cultivated GtoCFE 


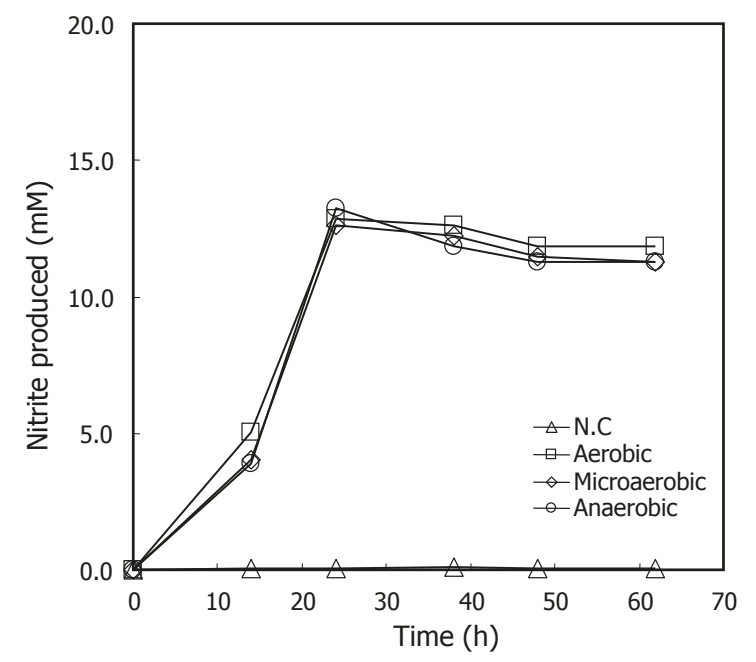

Figure 5 The effect of L-cysteine as a reducing agent on $\mathbf{S}$. toebii growth. L-cysteine $(0.025 \%$ final concentration) was added to $100 \mathrm{ml}$ PEPN broth containing $0.2 \mathrm{mg} \mathrm{ml}^{-1}$ of the same CFE prepared from microaerobically, anaerobically or aerobically cultured G. toebii with the experiment of figure 4. S. toebii was cultured in a $\mathrm{N}_{2}$ gas-flushed anoxic cultivation system at $60^{\circ} \mathrm{C}$. Squares, with CFE prepared from aerobically cultured $G$. toebii; diamonds, with CFE prepared from microaerobically cultured G. toebii; circles, with CFE prepared from anaerobically cultured $G$. toebii; triangles, without CFE (as a negative control, N.C.). S. toebii growth was monitored by measuring accumulated nitrite in culture broth.

could aid in constructing the initial conditions for growth of S. toebii.

\section{Discussion}

The GtoCFE prepared from the lag and exponential growth phases supported similar growth of $S$. toebii to the GtoCFE prepared from the stationary growth phase (Figure 1). The doubling times were parallel at each exponential growth stage of S. toebii. Figure 4 also shows that almost all of the GtoCFEs prepared at various oxygen tensions caused similar optimum growth. Both results demonstrate that sytoGSFs are constantly produced in G. toebii. This ubiquitous property of sytoGSFs strongly suggests the possibility that sytoGSFs may be essential material in G. toebii as well as in S. toebii. Since these two bacteria belong to different genera, we consider that sytoGSFs may be vital and fundamental material in Firmicutes and Proteobacteria. Moreover, the CFE of Escherichia coli, Bacillus subtilis and Geobacillus kaustophilus also show similar growth-supporting effects to $S$. toebii [20]. This prevalent existence in many other bacteria and the putative vital property in both G. toebii and $S$. toebii strongly suggest that $S$. toebii may not produce certain essential compounds for growth and proliferation due to either the absence of genes encoding essential biosynthetic pathways or silence of expression of proteins to produce sytoGSFs.

$S$. toebii cannot grow at atmospheric oxygen concentrations. In contrast, its partner bacterium G. toebii is a facultative aerobe that prefers aerobic over anaerobic growth conditions [22]. The discrepancy in oxygen tension for optimal growth of these two commensal bacteria raises interesting questions about how they interact directly and whether G. toebii also produces sytoGSFs under microaerobic or anaerobic condition. The discrepancy between these bacteria also provides a clue to the extended lag times of $S$. toebii cultivated with the CFEs of anaerobically or microaerobically cultured G. toebii. Generally, the physiological response to oxidative stress of ROS has been well studied in bacteria, especially anaerobic bacteria. For example, Clostridium perfringens and Desulfovibrio gigas elicit such protective responses at early stages of growth $[23,24]$. Furthermore, Lcysteine is thought to be an effective reducing agent at less than $0.05 \%$ in a culture broth [25]. As predicted, the extended lag times of $S$. toebii cultivated with CFEs prepared from microaerobically and anaerobically cultured G. toebii were reduced by direct supplementation with $0.025 \%$ L-cysteine to the S. toebii culture broth. Because the doubling time of all three GtoCFEs during exponential growth phases did not change, we assume that L-cysteine reduced the existence of ROS/RNS in the culture medium at the initial growth stage for $S$. toebii. Therefore, we suppose that the ROS/RNS scavenger proteins in GtoCFEs of aerobically cultured G. toebii support growth of $S$. toebii during the lag phase. Genome sequence analysis of G. kaustophilus, which is closely related to $G$. toebii, revealed several genes encoding three superoxide dismutases (GK2288, GK2457 and GK2933), two catalases (GK1710 and GK3036), two peroxidases (GK1785 and GK2787) and an alkyl hydroperoxide reductase homologue (GK0477) [26].

To verify this hypothesis, we examined the activity of catalase and peroxidase in the cell-free extracts that prepared from aerobically and anaerobically cultivated $G$. toebii. In Figure $6, \mathrm{H}_{2} \mathrm{O}_{2}$ in reaction mixture was rapidly diminished at the aerobically prepared GtoCFE, whereas the change of $\mathrm{H}_{2} \mathrm{O}_{2}$ concentration was gently decreased at the anaerobically prepared GtoCFE. This result supports that the elimination of ROS/RNS in the culture broth by those enzymes of helper bacteria promotes the growth of commensal symbiotic bacterium, S. toebii at its lag phase. These findings can also explain how $S$. toebii and G. toebii co-exist and how G. toebii supports the initial growth of S. toebii in environments such as compost and animal faeces. However, only construction of microaerobic and anaerobic conditions by G. toebii in the surrounding environment is not enough for the 


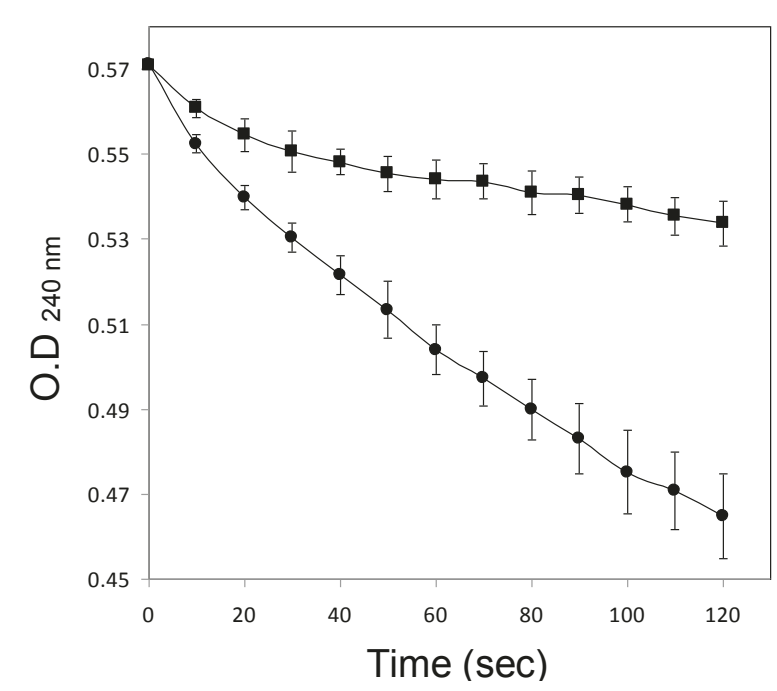

Figure 6 The catalase and peroxidase activity in the GtoCFEs prepared from aerobically and anaerobically cultivated $G$. toebii. The breakdown $\mathrm{H}_{2} \mathrm{O}_{2}$ with aerobically prepared GtoCFE (closed circle) and anaerobically prepared GtoCFE (closed square) was directly monitored at absorbance $240 \mathrm{~nm}$ for $120 \mathrm{~s}$ under $25^{\circ} \mathrm{C}$, respectively. The results represent the mean ( \pm standard deviation) of five independent measurements.

growth of $S$. toebii because this bacterium does not grow without special supplements such as GtoCFEs.

In the last decade, cell-signaling compounds were identified in Euplotes raikovi and Micrococcus luteus, which are pathogenic bacteria and the compounds are proposed to mediate communication within species to control cell population growth in response to various stimuli [27-29]. The growth of $S$. toebii appears to be stimulated and induced by sytoGSFs from G. toebii. However, we propose that sytoGSFs produced from G. toebii differ from the above quorum-sensing factors. $S$. toebii continuously required GtoCFE during all growth stages, and the growth rate was dependent on the concentration of sytoGSFs in the GtoCFE (Figures 2, and 3). The observation that the doubling time was persistently extended with insufficient concentrations of sytoGSF suggests a nutrient-like character for sytoGSFs rather than a signaling character.

The most interesting issue about $S$. toebii study is what the sytoGSF is. However, we couldn't characterize and purify the sytoGSF in spite of extensive and exhaustive studies because of unstable cultivation results and low reproducibility of the growth of $S$. toebii in an artificial condition. Nevertheless, we suppose that properties of the growth-supporting factor for S. toebii and S. thermophilum are quite different because the growth-supporting factor for S. thermophilum (sythGSF) is existed in a culture supernatant whereas sytoGSF is existed in a cell-free extract [20]. These two components also showed different biochemical properties such as molecular weight, heat stability and proteinase sensitivity [20]. Recently, Ueda et al suggested a possibility of syntrophic relationship between $S$. thermophilum and Bacillus strain $S$ [30]. They focused carbonic anhydrase of the helper bacterium which reversibly converts $\mathrm{CO}_{2}$ to carbonate ion because no homolog of carbonic anhydrase was observed in genome sequence of $S$. thermophilum. They assumed that the carbonate ion and/or $\mathrm{CO}_{2}$ converted by carbonic anhydrase of the helper bacterium supports the growth of $S$. thermophilum. Additional supplement of high concentration of $\mathrm{CO}_{2}$ gas into the culture system promoted approximately $10 \%$ of the maximal growth of $S$. thermophilum. However, no significant growth of $S$. toebii was observed under the same $\mathrm{CO}_{2}$ concentration in the culture system without GtoCFE or culture supernatant of G. toebii. Taken together, we carefully concluded that the $\mathrm{CO}_{2}$ effect is not working for $\mathrm{S}$. toebii and the growth-supporting factor for two Symbiobacterium is different although they belong to the same genus.

\section{Conclusion}

The study of commensal interrelationships between two different bacterial genera based on the growth of $S$. toebii with various CFEs of G. toebii suggests that sytoGSFs are ubiquitously expressed in G. toebii and may be essential compounds Firmicutes and Proteobacteria. Growth of $S$. toebii depended on the concentration of GtoCFE, indicating that sytoGSF has nutrient-like characters rather than quorum-sensing character. Taken together, we suggest that $S$. toebii may not be able to produce sytoGSFs due to silence or lack of certain biosynthesis machinery and uptakes the anonymous vital compound for growth from environment or partner bacteria which share the element. Additionally, the retarded lag phases of $S$. toebii by GtoCFEs of microaerobically or anaerobically cultivated G. toebii and the complementary effect of reducing agent, L-cysteine for the growth of $S$. toebii suggest a possible commensal interaction that ROS/RNS scavenger enzymes expressed in G. toebii under aerobic condition play an important role for the initial growth of S. toebii.

\section{Methods}

Bacterial strains, culture media and reagents

S. toebii SC-1 DSM 15906 (KCTC 0685BP) and G. toebii DSM 14590 were isolated from Korean hay compost (toe-bi). PEP broth was prepared by mixing $6 \mathrm{~g}$ $\mathrm{KH}_{2} \mathrm{PO}_{4}, 2 \mathrm{~g} \mathrm{~K}_{2} \mathrm{HPO}_{4}, 5 \mathrm{~g}$ polypeptone and $10 \mathrm{~g}$ yeast extract in 1.0 liter distilled water; the $\mathrm{pH}$ was adjusted to 7.0 with $\mathrm{NaOH} . \mathrm{NaNO}_{3}$ was added to PEP broth at a final concentration of $30 \mathrm{mM}$ to produce PEPN broth, and this was used to cultivate S. toebii. Agar plates were made by adding $20 \mathrm{~g}$ agar powder to 1.0 liter PEPN 
broth. Luria-Bertani (LB) broth for G. toebii was prepared by combining $10 \mathrm{~g}$ tryptone, $5 \mathrm{~g} \mathrm{NaCl}$ and $5 \mathrm{~g}$ yeast extract in 1.0 liter distilled water and adjusting the $\mathrm{pH}$ to 7.0. $\mathrm{NaNO}_{3}, \mathrm{NaNO}_{2}$ and kanamycin were purchase from Wako Pure Chemical Industries (Osaka, Japan). Sulphanilamide and $N$-(1-naphthyl)-ethylenediamine for nitrite quantification were purchased from Sigma-Aldrich (St. Louis, MO, USA). Yeast extract and Bacto $^{\mathrm{TM}}$ Tryptone were purchased from Becton Dickinson (Sparks, MD, USA) and polypeptone and other chemicals for cultivation were obtained from Nacalai Tesque (Kyoto, Japan).

\section{Cultivation of S. toebii and G. toebii}

An anaerobic culture system was constructed with a GasPak ${ }^{\mathrm{TM}}$ Plus Anaerobic System Envelope (BBL ${ }^{\mathrm{TM}}$ Cat. No. 271040; Becton Dickinson Microbiology Systems, Cockeysville, MD, USA), which kept the $\mathrm{H}_{2}: \mathrm{CO}_{2}$ gas ratio at 90:10, with $<0.2 \% \mathrm{O}_{2}$ contained in an anaerobic jar (BBL ${ }^{\text {TM }}$ GasPak 100 ${ }^{\text {TM }}$ Anaerobic System; Becton Dickinson Microbiology Systems). Anaerobic conditions were confirmed using Dry Anaerobic Indicator Strips (BBL ${ }^{\text {TM }}$ Cat. No. 271051; Becton Dickinson Microbiology Systems). For other anoxic culture systems, 0.1- to 2.0-liter glass bottles were sealed with silicon packing and the air inside the bottles was purged with nitrogen gas for 1 min. Bottles were then charged with the same gas for an additional $1 \mathrm{~min}$ using a syringe and a filter $\left(\right.$ Millex $^{\mathbb{B}} \mathrm{GV}$ $0.22 \mu \mathrm{m}$; Millipore, Cork, Ireland) at 0.2 Mpa. For microaerobic cultures, a CampyPak ${ }^{\mathrm{TM}}$ Plus Microaerophilic System Envelope (BBL ${ }^{\text {TM }}$ Cat. No. 271045; Becton Dickinson Microbiology Systems) was used in place of the anaerobic system envelope in the same type of jar.

S. toebii was pre-cultured with $100 \mathrm{ml}$ PEPN broth containing $100 \mu \mathrm{g} \mathrm{ml}^{-1}$ GtoCFE prepared from aerobically cultivated G. toebii and $50 \mu \mathrm{g} \mathrm{ml}^{-1}$ kanamycin in the anaerobic culture system at $60^{\circ} \mathrm{C}$ for $12 \mathrm{~h}$. One percent of the culture broth was inoculated into the same culture medium which pre-incubated at $60^{\circ} \mathrm{C}$ over $1 \mathrm{~h}$ and cultured the broth anaerobically at the same temperature for a sufficient time depending on each experiment. The CFE of G. toebii was supplied into the culture broth according to the needs of each experiment. Aerobic cultivation of G. toebii was carried out with LB broth in an Erlenmeyer flask at $60^{\circ} \mathrm{C}$ overnight, or for the time required to prepare various GtoCFEs. $G$. toebii was cultivated microaerobically and anaerobically under the same conditions as S. toebii. The cultures were supplemented with $30 \mathrm{mM}$ sodium nitrate as an electron acceptor for anaerobic respiration.

\section{Preparation of CFEs of G. toebii}

To prepare culture condition-dependent GtoCFEs, G. toebii was cultivated at $60^{\circ} \mathrm{C}$ overnight in 1.0 liter of $\mathrm{LB}$ broth either with vigorous shaking for aeration or in a jar as described above without agitation for anaerobic and microaerobic cultivation. The cells were harvested at $7000 \times g$ for $10 \mathrm{~min}$ at $4^{\circ} \mathrm{C}$ after $2 \mathrm{~h}, 9 \mathrm{~h}$ and $24 \mathrm{~h}$ to prepare GtoCFEs for lag, exponential and stationary growth stages, respectively. Pellets were washed twice with phosphate-buffered saline (PBS, $\mathrm{pH}$ 7.4) and resuspended in $20 \mathrm{ml}$ PBS. The cells were disrupted ultrasonically (UD-210: output 8, duty 70; Tomy, Tokyo, Japan) three times for $10 \mathrm{~min}$ on ice with stirring. After centrifugation at $7000 \times g$ for $20 \mathrm{~min}$ to remove cell debris, the crude extract was filter-sterilised with a $0.2-\mu \mathrm{m}$ pore filter (Minisart-plus, $0.2 \mu \mathrm{m}$ CA-membrane+GF-prefilter; Sartorius AG, Göttingen, Germany). This GtoCFE was used as a supplement for S. toebii cultures. The protein concentration of the GtoCFEs was estimated by the Bradford method using bovine serum albumin as a standard [31]. The concentration of GtoCFE ranged from 20 to $30 \mathrm{mg} \mathrm{ml}^{-1}$. To investigate the growth-supporting effect of sytoGSFs, the sytoGSFs contained in GtoCFEs were normalised to the protein concentration of the GtoCFEs.

\section{Measurement of bacterial growth}

S. toebii growth was monitored by three independent methods: direct cell counting, optical density of the culture broth and accumulation of nitrite. Cells were counted in a 0.02-mm-deep bacteria counting chamber (Erma Co., Tokyo, Japan) under a phase-contrast microscope (BX40F; Olympus Optical Co. Ltd., Tokyo, Japan). Optical density $(600 \mathrm{~nm})$ was measured for each culture broth with a spectrophotometer (U-3000; Hitachi, Tokyo, Japan). The concentration of nitrite that accumulated in the medium after conversion from nitrate by $S$. toebii was measured using the modified colorimetric method described below. The growth of G. toebii was monitored by measuring the optical density at $600 \mathrm{~nm}$.

\section{Quantification of nitrite}

S. toebii converts nitrate to nitrite under nitrate-reducing conditions. Nitrite accumulates in the culture broth because it cannot be converted to $\mathrm{N}_{2}$ or $\mathrm{NH}_{4}{ }^{+}$[21] . Therefore, S. toebii growth can be monitored indirectly by measuring accumulated nitrite in the culture broth. A modified colorimetric method was used for this purpose: $20 \mu \mathrm{l}$ of sulphanilamide solution (1\% sulphanilamide in $0.6 \mathrm{~N} \mathrm{HCl}$ ) was added to $0.9 \mathrm{ml}$ of serially diluted culture broth, and the mixtures were kept at room temperature for $4 \mathrm{~min}$ after vigorous agitation. Then, $20 \mu \mathrm{l}$ of $0.1 \% N$-(1-naphthyl)-ethylenediamine solution was added to each reaction, and the solutions were kept at room temperature in the dark for $30 \mathrm{~min}$. Coupling of the nitrite-sulphanilamide complex to $\mathrm{N}$-(1naphthyl)-ethylenediamine caused the solution to turn 
pink. Absorbance at $543 \mathrm{~nm}$ was converted to nitrite concentration using a standard curve constructed by the known amounts of sodium nitrite.

\section{Catalase and peroxidase assay}

G. toebii was cultivated by stationary phase at anaerobic system or aerobic system in LB broth with or without $30 \mathrm{mM}$ sodium nitrate, respectively. Each protein concentration was normalised with PBS buffer as $20 \mathrm{mg} / \mathrm{ml}^{-}$ ${ }^{1}$ by Bradford method after cell lysis. The activity of catalase and peroxidase was measured by breakdown rate of $\mathrm{H}_{2} \mathrm{O}_{2}$ in a reaction mixture [32]. The cell-free extracts were further diluted to a hundredth with 50 $\mathrm{mM}$ potassium phosphate buffer $(\mathrm{pH} \mathrm{7.0)}$ and then 10 $\mu \mathrm{l}$ of the cell-free extract corresponding to $2.0 \mu \mathrm{g}$ of total proteins was reacted with $10 \mathrm{mM} \mathrm{H}_{2} \mathrm{O}_{2}$ in $1.0 \mathrm{ml}$ of $50 \mathrm{mM}$ potassium phosphate buffer $(\mathrm{pH} 7.0)$ under $25^{\circ} \mathrm{C}$. The change of $\mathrm{H}_{2} \mathrm{O}_{2}$ concentration directly monitored by UV spectrometer (U-3000; Hitachi, Tokyo, Japan) at absorbance $240 \mathrm{~nm}$ from 3 - $123 \mathrm{~s}$ after the onset of reaction.

\section{Abbreviations}

CFE: cell-free extract; GtoCFE: cell-free extract of G. toebii; GSF: growthsupporting factor; sytoGSF: growth-supporting factor for Symbiobacterium toebii; sythGSF: growth-supporting factor for Symbiobacterium thermophilum; ROS: reactive oxygen species; RNS: reactive nitrogen species.

\section{Acknowledgements}

The work was supported by the 2011 research fund of Kookmin University and by the 'Seoul R\&BD Program (10580)' in Korea.

\section{Author details \\ 'Department of Biological Sciences, Graduate School of Science, Osaka University, Osaka 560-0043, Japan. ${ }^{2}$ BioLeaders Corporation, 559 Yongsan- dong, Yuseong-gu, Daejeon 350-500, Korea. ${ }^{3}$ Department of Advanced Fermentation Fusion Science and Technology, Kookmin University, Seoul 136-702, Korea. ${ }^{4}$ RIKEN SPring-8 Center, 1-1-1 Kouto, Sayo-cho, Sayo-gun, Hyogo 679-5148, Japan. ${ }^{5}$ Department of Biological Sciences, University of Calgary, Calgary, Alberta, T2N 1N4, Canada.}

\section{Authors' contributions}

KK designed and interpreted data and wrote the manuscript. JJK assisted in the data acquisition. RM helped revising the manuscript. SK designed and supervised the analyses and corrected the manuscript. MHS designed project conception and helped to revise the manuscript. All authors read and approved the final manuscript.

\section{Competing interests}

The authors declare that they have no competing interests.

Received: 22 May 2011 Accepted: 24 October 2011

Published: 24 October 2011

\section{References}

1. Hugenholtz P, Goebel BM, Pace NR: Impact of culture-independent studies on the emerging phylogenetic view of bacterial diversity. J Bacteriol 1998, 180(18):4765-4774

2. Pace NR: A molecular view of microbial diversity and the biosphere. Science 1997, 276(5313):734-740.

3. Amann Rl, Ludwig W, Schleifer KH: Phylogenetic identification and in situ detection of individual microbial cells without cultivation. Microbiol Rev 1995, 59(1):143-169.
4. Lee N, Nielsen PH, Andreasen KH, Juretschko S, Nielsen JL, Schleifer KH, Wagner M: Combination of fluorescent in situ hybridization and microautoradiography-a new tool for structure-function analyses in microbial ecology. Appl Environ Microbiol 1999, 65(3):1289-1297.

5. Nielsen JL, Christensen D, Kloppenborg M, Nielsen PH: Quantification of cell-specific substrate uptake by probe-defined bacteria under in situ conditions by microautoradiography and fluorescence in situ hybridization. Environ Microbiol 2003, 5(3):202-211.

6. Friedrich MW: Stable-isotope probing of DNA: insights into the function of uncultivated microorganisms from isotopically labeled metagenomes. Curr Opin Biotechnol 2006, 17(1):59-66.

7. Whiteley AS, Manefield M, Lueders T: Unlocking the 'microbial black box' using RNA-based stable isotope probing technologies. Curr Opin Biotechnol 2006, 17(1):67-71.

8. Adamczyk J, Hesselsoe M, Iversen N, Horn M, Lehner A, Nielsen PH, Schloter M, Roslev P, Wagner M: The isotope array, a new tool that employs substrate-mediated labeling of rRNA for determination of microbial community structure and function. Appl Environ Microbiol 2003, 69(11):6875-6887.

9. Shigenobu S, Watanabe H, Hattori M, Sakaki Y, Ishikawa H: Genome sequence of the endocellular bacterial symbiont of aphids Buchnera sp. APS. Nature 2000, 407(6800):81-86.

10. Tamas I, Klasson LM, Sandstrom JP, Andersson SG: Mutualists and parasites: how to paint yourself into a (metabolic) corner. FEBS Lett 2001, 498(2-3):135-139.

11. Xu J, Bjursell MK, Himrod J, Deng S, Carmichael LK, Chiang HC, Hooper LV, Gordon J: A genomic view of the human-Bacteroides thetaiotaomicron symbiosis. Science 2003, 299(5615):2074-2076.

12. Vallesi A, Giuli G, Bradshaw RA, Luporini P: Autocrine mitogenic activity of pheromones produced by the protozoan ciliate Euplotes raikovi. Nature 1995, 376(6540):522-524.

13. Kaeberlein T, Lewis K, Epstein SS: Isolating "uncultivable" microorganisms in pure culture in a simulated natural environment. Science 2002, 296(5570):1127-1129.

14. Rhee SK, Lee SG, Hong SP, Choi YH, Park JH, Kim CJ, Sung MH: A novel microbial interaction: obligate commensalism between a new gramnegative thermophile and a thermophilic Bacillus strain. Extremophiles 2000, 4(3):131-136

15. Rhee SK, Jeon CO, Bae JW, Kim K, Song JJ, Kim JJ, Lee SG, Kim HI, Hong SP, Choi $\mathrm{YH}$, et al: Characterization of Symbiobacterium toebii, an obligate commensal thermophile isolated from compost. Extremophiles 2002, 6(1):57-64.

16. Rhee SK, Hong SP, Bae JW, Jeon CO, Lee SG, Song JJ, Poo H, Sung MH: Estimation of distribution of a commensal thermophile in soil by competitive quantitative PCR and terminal restriction fragment length polymorphism analysis. Journal of Microbiology and Biotechnology 2001, 11(6):940-945.

17. Bae JW, Kim JJ, Jeon CO, Kim K, Song JJ, Lee SG, Poo H, Jung CM, Park YH, Sung $\mathrm{MH}$ : Application of denaturing gradient gel electrophoresis to estimate the diversity of commensal thermophiles. Journal of Microbiology and Biotechnology 2003, 13(6):1008-1012.

18. Bae JW, Rhee SK, Park JR, Kim BC, Park YH: Isolation of uncultivated anaerobic thermophiles from compost by supplementing cell extract of Geobacillus toebii in enrichment culture medium. Extremophiles 2005.

19. Ueda K, Ohno M, Yamamoto K, Nara H, Mori Y, Shimada M, Hayashi M, Oida $H$, Terashima $Y$, Nagata $M$, et al: Distribution and diversity of symbiotic thermophiles, Symbiobacterium thermophilum and related bacteria, in natural environments. Appl Environ Microbiol 2001, 67(9):3779-3784

20. Kim JJ, Masui R, Kuramitsu S, Seo JH, Kim K, Sung MH: Characterization of growth-supporting factors produced by Geobacillus toebii for the commensal thermophile Symbiobacterium toebii. J Microbiol Biotechnol 2008, 18(3):490-496.

21. Sung MH, Bae JW, Kim JJ, Kim K, Song JJ, Rhee SK, Jeon CO, Choi YH, Hong SP, Lee SG, et al: Symbiobacterium toebii sp. nov., Commensal Thermophile Isolated from Korean Compost. Journal of Microbiology and Biotechnology 2003, 13(6):1013-1017.

22. Sung MH, Kim H, Bae JW, Rhee SK, Jeon CO, Kim K, Kim JJ, Hong SP, Lee SG, Yoon JH, et al: Geobacillus toebii sp. nov., a novel thermophilic bacterium isolated from hay compost. Int J Syst Evol Microbiol 2002, 52(Pt 6):2251-2255. 
23. Jean $\mathrm{D}$, Briolat V, Reysset G: Oxidative stress response in Clostridium perfringens. Microbiology 2004, 150(Pt 6):1649-1659.

24. Fareleira P, Santos BS, Antonio C, Moradas-Ferreira P, LeGall J, Xavier AV, Santos H: Response of a strict anaerobe to oxygen: survival strategies in Desulfovibrio gigas. Microbiology 2003, 149(Pt 6):1513-1522.

25. Levett PN: Anaerobic Microbiology; A Practical Approach. In Anaerobic culture methods. Volume 1.. 1 edition. Edited by: Willis AT. Oxford New York Tokyo: Oxford University Press; 1991.

26. Takami H, Takaki Y, Chee GJ, Nishi S, Shimamura S, Suzuki H, Matsui S, Uchiyama I: Thermoadaptation trait revealed by the genome sequence of thermophilic Geobacillus kaustophilus. Nucleic Acids Res 2004, 32(21):6292-6303.

27. Ji G, Pei W, Zhang L, Qiu R, Lin J, Benito Y, Lina G, Novick RP: Staphylococcus intermedius produces a functional agr autoinducing peptide containing a cyclic lactone. J Bacteriol 2005, 187(9):3139-3150

28. Kleerebezem M, Quadri LE, Kuipers OP, de Vos WM: Quorum sensing by peptide pheromones and two-component signal-transduction systems in Gram-positive bacteria. Mol Microbiol 1997, 24(5):895-904.

29. Hastings JW, Greenberg EP: Quorum sensing: the explanation of a curious phenomenon reveals a common characteristic of bacteria. J Bacteriol 1999, 181(9):2667-2668.

30. Ueda K, Beppu T: Lessons from studies of Symbiobacterium thermophilum, a unique syntrophic bacterium. Biosci Biotechnol Biochem 2007, 71(5):1115-1121.

31. Bradford M: A rapid and sensitive method for the quantitation of microgram quantities of protein utilizing the principle of protein dye binding. Anal Biochem 1976, 72:248-254

32. Beers RF Jr, Sizer IW: A spectrophotometric method for measuring the breakdown of hydrogen peroxide by catalase. J Biol Chem 1952, 195(1):133-140.

doi:10.1186/1756-0500-4-437

Cite this article as: Kim et al:: A commensal symbiotic interrelationship for the growth of Symbiobacterium toebii with its partner bacterium, Geobacillus toebii. BMC Research Notes 2011 4:437.

\section{Submit your next manuscript to BioMed Central} and take full advantage of:

- Convenient online submission

- Thorough peer review

- No space constraints or color figure charges

- Immediate publication on acceptance

- Inclusion in PubMed, CAS, Scopus and Google Scholar

- Research which is freely available for redistribution

Submit your manuscript at www.biomedcentral.com/submit
C Biomed Central 